\title{
INFORMATION TECHNOLOGY SPEEDING UP CIRCULATION OF RURAL ECONOMY
}

\author{
Ranbing Yang ${ }^{1,2}$, Suhua Liu $^{3}$, Jie Liang ${ }^{2}$, Shuqi Shang ${ }^{2, *}$ \\ I Engineering School, Shenyang Agricultural University, Shenyang, China, 110161 \\ 2 School of Mechanical and Electric Engineering, Qingdao Agricultural University, Qingdao, \\ China, 266109 \\ 3 Automation Engineering School, Qingdao Technological University, Qingdao, China, \\ 266109 \\ * Corresponding author, Address: School of Mechanical and Electric Engineering, Qingdao \\ Agricultural University, Qingdao, 266109, P. R. China, Tel: +86-532-86080842, Fax: +86- \\ 532-86080452, Email: yangranbing@163.com (No. of Fund Item: 2006BAD28B06)
}

Abstract: Nowadays, the information in the field of Chinese rural economy circulation is not only plentiful but complicated. The current network information technology is insufficient when dealing with the supply-demand relationship, and it cannot fundamentally meet the real needs of rural economy. Based on the current situation of rural economy, this paper puts forward ways to establish, using computers and information technology, a new rural economic information exchange platform. The platform can realize Informatization of rural economy through the database processing technology and Geospatial Information Grid method, thus fundamentally solves Chinese information shortage.

Keywords: rural economy, information technology, database, geospatial information grid

\section{INTRODUCTION}

With the development of productive forces, rural economy has developed rapidly in recent years; rural areas have undergone tremendous changes, and gradually changed the backwardness of "natural economy". However, at present, most of Chinese rural areas are still no large-scale production, and 
belong to the basic self-production and sales of an inward-looking economy (Zhu Naifen, 2007). The main features of this kind of economic activities are:

(1) The economic structure of exchange is miscellaneous. Economic activities of most commodities are only between suppliers and customers. Forms of commodities are diverse, and the commodities are with small quantities of miscellaneous;

(2) Demand information seriously lags behind. As the product quantities of both suppliers and customers are too small, the existing ways of information circulation cannot meet the demand. The primitive market is in a "blind" state, where both suppliers and customers can only try to do unknown commodity activities in prescriptive time, and in this case, the economic information cannot be exchanged timely and effectively;

(3) TV, newspapers and other media are mainly for cost-efficient commodities of large quantities, and do not yet meet the exchange of information in rural areas, which is complex, chaotic and small.

In the global Informatization and Digital background, information technology has become indispensable means to promote agricultural economic development (Su Qizhi, 2007). Only full use of information technology, can fundamentally promote rural economic development and circulation.

\section{THE INSUFFICIENCY OF EXISTING NETWORK INFORMATION SERVING FOR RURAL ECONOMIC ACTIVITIES}

Taking a panoramic view of various network services systems in China, most of them take diffusive ways to disseminate information. Suppliers and customers directly disseminate the information to whole country and even the whole world through internet.

In this way, there are several problems:

(1) Information waste. If commodities for supply or for demand are too small or too little, it is unnecessary for the overall situation of direct distribution. For instance, farmers in Tianjin want to disseminate information to sell 100 kilograms of apples, which is effective information in some areas of Tianjin. However, this information is redundant for other regions of Tianjin and even the whole country.

(2) Failure to establish effective communication. For example, Guangdong farmers issue a district desires 10 kilograms of strawberries. Strawberry has certain durability, coupled with less demand, so this information can only be effective within $50 \mathrm{~km}$. Chinese Agricultural Information Network, relative to local network, has done a great 
improvement in this aspect, as illustrated in Figure 1, but there are still above shortages, particularly in rural areas, where do not facilitate transport. The rage of effective information should be smaller, which is clearly unable to meet everyday needs of the farmers, if only confined to the provinces, municipalities (Pang Jiangang, 2007).

(3) Information region is too broad. Commodity information includes time efficiency and the range, but existing information network platform only pays attention to the time efficiency, ignoring range of information.

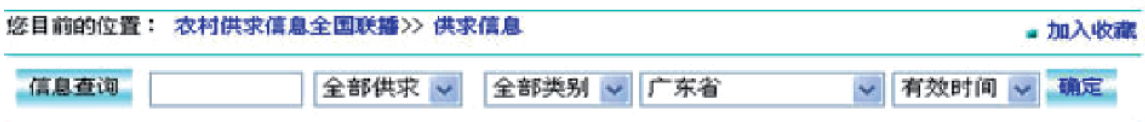

Figure 1. Traditional information exchange platform

\section{RURAL ECONOMIC INFORMATION EXCHANGE PLATFORM}

For rural economic information is cumbersome and complex, rural traffic conditions is relatively poor, and information is with time efficiency and the regional characteristics, a new rural economic information exchange platform is established here, and the whole structure is depicted in Figure 2.

Relative to other agricultural information platform, the new one adds geographic information processing module on the basis of the time information processing module. Figure 3 is the corresponding search engine. The main features of the system are given in the following sections.

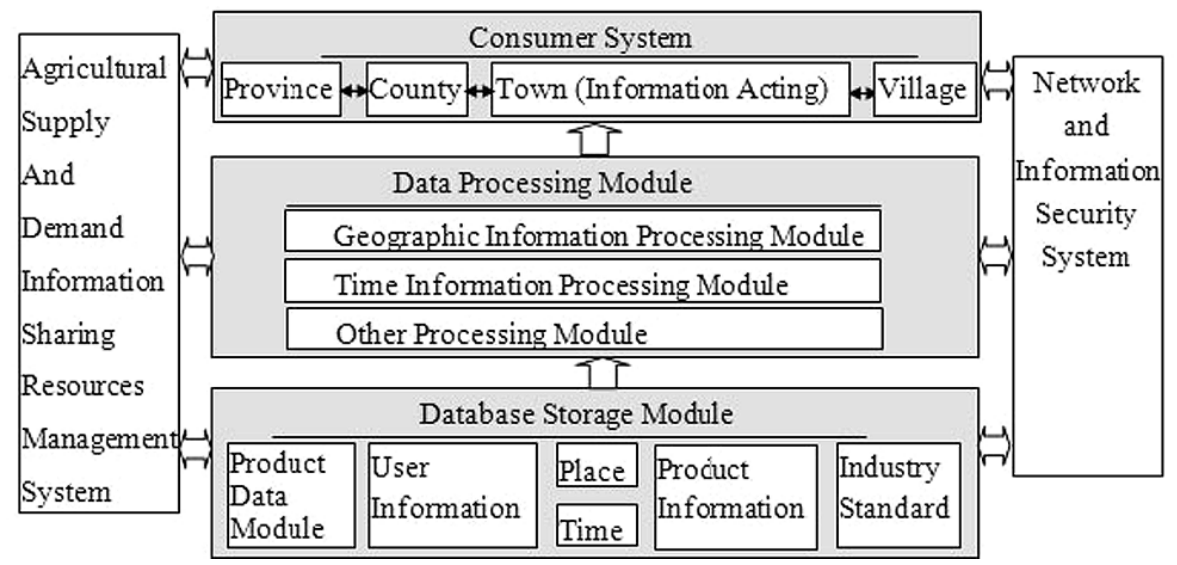

Figure 2. The whole structure of the new information exchange platform 
供求 查 询 (Supply and Demand Inquiry)

\begin{tabular}{|c|c|c|c|}
\hline $\begin{array}{l}\text { 产品信息 } \\
\text { Product Information }\end{array}$ & $\begin{array}{l}\text { 地点 } \\
\text { Place }\end{array}$ & & $\begin{array}{c}\text { 讧第 } \\
\text { Browse }\end{array}$ \\
\hline 求 (Dem and) - 崖布范围 & $\begin{array}{l}\text { 公里以内 } \\
\text { ko (Within) }\end{array}$ & $\begin{array}{l}\text { 时间 } \\
\text { Time }\end{array}$ & $\begin{array}{l}\text { 天 } \\
\text { Day }(s)\end{array}$ \\
\hline 排列顺序 ( 需求信息) & 地点 $\rightarrow$ 时间 $\omega_{i s \operatorname{san}}$ & $\rightarrow$ Time) $=$ & $\begin{array}{c}\text { 确定 } \\
\text { OK }\end{array}$ \\
\hline
\end{tabular}

Figure 3. The new search engine

\subsection{Information Point}

In rural areas, distance factor is the primary factor among product information because of vast territory and inconvenient transportation. Therefore, demand-side should firstly provide geographic information of locations to geographic information processing module, that is to say, after determining the coordinate base point, one can get the product information in a certain area. Geographic information processing module is able to provide the region according to customers' IP addresses, and users can also revise region depending on specific circumstances. In order to get more detailed product information, geographic information should not be too general, and the smallest level is usually village. Time information point is, as the same as traditional rural economic information exchange platform, using the demand time as base point.

\subsection{Information Demanding Domain}

Traditional rural information exchange platform only vaguely defines region of inquiring information, which is useful for commodities with large quantity or great value. However, in daily life, particularly in rural areas, most of the actual transaction commodities are less valuable. Traffic conditions and commodity nature determine the regional and temporal differences. If farmers need five kilograms of cabbage, the scope of transactions cannot be too large, and dissemination of information should be within the radius of $10 \mathrm{~km}$ around the location of the farmers, with effective time normally not more than seven days.

\subsection{Information Sequencing}

In life, when there is a large number of information dissemination, simple, quick access to the information is essential. As to commodity information, distance and time of supply and demand in rural areas are very crucial factors; therefore, it should be based on different needs to establish different information sequencing. Here are two categories: "distance $\rightarrow$ time" and 
"time $\rightarrow$ distance" (Wang Na, 2007), and the users can determine different priority level to the two factors according to different needs. Traditional rural information exchange platform only pays attention to the time factor, overlooked the distance factor (Chen Wei, 2007). In rural areas, farmers are often based on economic interests, and choose distance factors at the very beginning. Figure 4 is information query results using distance factors as the priority level.

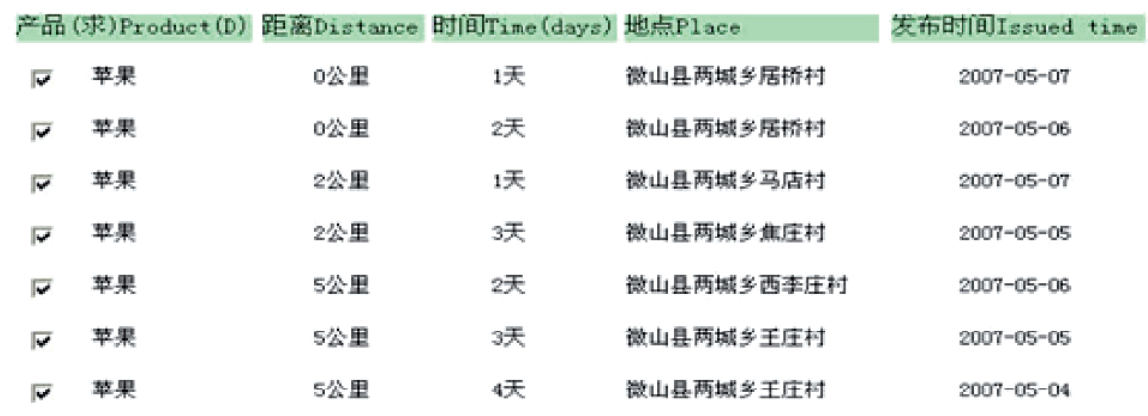

Figure 4. Information query results

\section{GEOGRAPHIC INFORMATION DIGITAL}

As the rapid development of the information technology, geographic information digital (Han Zhenbiao, 2007) has become inevitable. In rural economic activities, different distance is an important factor to be considered. In order to obtain detailed supply and demand information, it is necessary to carry on the digital information communication to the two places of supply and demand.

A vector maps is established in this paper by the ways shown in Table 5, in order to - according to latitude and longitude and taken village as data point basis - erect vector numerical information to the national map. Units here are kilometers, and along with the information development, the units can be even smaller.

Figure 5 is the map of some areas in Ji'ning area of Shandong Province. For example, a farmer in the place of the Bridge Village wants to inquire some commodity information, and his inquiry scope establishment is 5 kilometers, then the demanding scope should take the Bridge Village as the center, within surrounding area of a 5 kilometers circle.

All the issued information, whose location distance $\mathrm{D}$ from Bridge Village to be smaller than 5 kilometers, is the farmer's required one. Xilizhuang Village, Zongcundong Village, Madian Village, Jiaozhuang Village, Wangzhuang Village in Table 4 are in this scope. Then the information issued from these villages is classified according to distance $\mathrm{D}$. The distance 


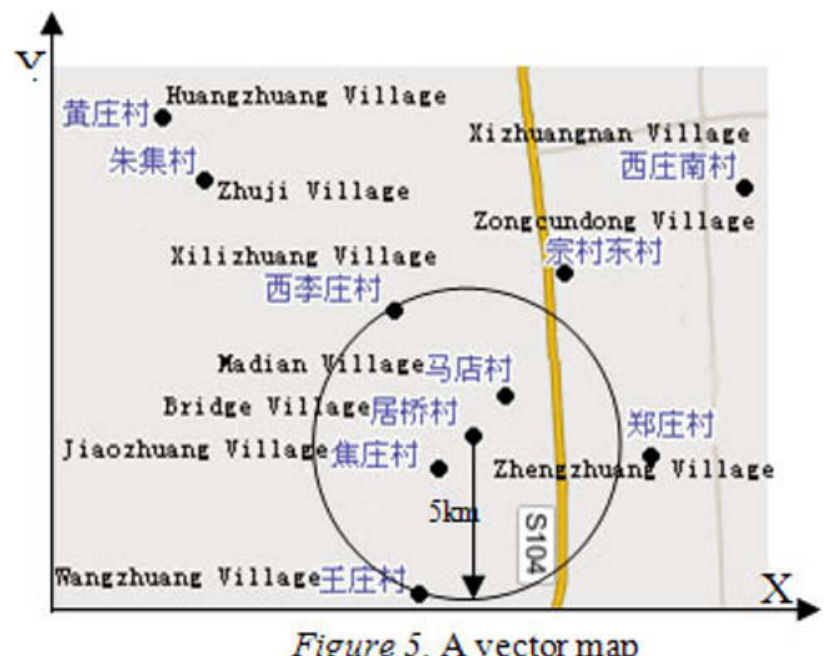

is calculated in this platform based on the Dijkstra's shortest searching algorithm. (YueYang, 1999) It has fully used the existing pile of data, reduced the data comparison frequency.

Concrete steps: Each spot has a pair of marking (d, p), D is the most short-path distance from source $s$ to selects $j$ (From the apex to its itself most short-path is the zero road [No arched road] Its length is equal to zero); $\mathrm{Pj}$ is in the short-path way from source $s$ to $j$ and is $j$ preceding. To selects $j$ from source $\mathrm{s}$ the most short-path algorithm unit process. The shortest path algorithm from source $\mathrm{s}$ to $\mathrm{j}$ for the basic process:

(1) Initialization. Point of Origin: $\mathrm{ds}=0$, ps empty; All other points: $\mathrm{di}=\infty, \mathrm{pi}=\infty$. Marker source $\mathrm{s}$, mind $\mathrm{k}=\mathrm{s}$, all other points as the unmarked.

(2) Testing the distance from all marked point $\mathrm{k}$ to the unmarked point $\mathrm{j}$ which direct linked, and setting: $\mathrm{dj}=\min [\mathrm{dj}, \mathrm{dk}+\mathrm{lkj}]$, and $\mathrm{lkj}$ is the direct link distance from the point $\mathrm{k}$ to $\mathrm{j}$.

(3) Next point selection. From all unmarked node, select the smallest $\mathrm{j}$ among the points $\mathrm{dj}$ : $\mathrm{di}=\min [\mathrm{dj}$, All unmarked point $\mathrm{j}]$ point $\mathrm{i}$ was selected as the shortest path to the point, and has set the marker.

(4) Preceding point in front of point $i$ found. Point $j^{*}$ direct linked to point $i$ is found from marked points, and taken as preceding point,. Set: $i=j^{*}$.

(5) Point i marked. If all points have marked, the algorithm fully launched, otherwise set $\mathrm{k}=\mathrm{i}$, to step (2), to continue.

\section{DYNAMIC DATABASE ESTABLISHMENT}

It is extremely widespread to establish the network dynamic database in the daily application, and most of existing websites use the dynamic information input. (Zhang Xiao, 2006) Moreover, most database input form 
that the majority of farmer information network platform used all may adapt in this network platform, and as to the needed code, this paper will no longer give unnecessary details. The difference is an added module of detailed locations of the user input, to the determination of the inquiry point in vector maps.

\section{SUMMARY AND OUTLOOK}

Rural information technology is an important way to realize agricultural and rural economic restructuring, and to increase the income of peasants. Based on the actual needs of farmers, this paper puts forward ways to establish a viable rural economic information exchange platform to solve the difficult problems that cannot handle by other media in the flow of rural economy. Along with rural network popularization, people can gradually gain the actual benefit from information technology, achieving the goal of increasing economic returns of agriculture and farmers' incomes.

This search engine can be used not only in agricultural product application, but also on the application promotion of daily life. For instance, if vector map is established for local supermarkets, stores, hotels, and so on, people at home can communicate with each other and exchange information in a timely manner and efficient way.

\section{REFERENCES}

Chen Wei, RSS. A technology to syndicate information. Computer Knowledge and Technology, 2007(1): 46-47

Han Zhenbiao. Mapxtreme2004 based query system of webgis vectorgraph. Geomatics \& Spatial Information Technology, 2007(2): 36-39

Pang Jiangang. The applied research of information construction in countryside. Market Modernization, 2007, 503: 369-370

Su Qizhi. Strengthening of rural information network to promote rural economic development. China Well-off Rural Technology, 2007(6): 55-56

Wang Na. Discussion about the network information mining. Library Work in Colleges and Universities, 2007, 27(3): 38-40

YueYang. An efficient implementation of shortest path algorithm based on dijkstra algorithm. Computer Applications and Software, 1999, 24(3): 209-212

Zhu Naifen. The countermeasure and suggestion on the strength the agriculture information system. Information Science, 2007, 25(3): 364-367

Zhang Xiao. The Example of PHP+ MySQL+ Dreamweaver, Tsinghua University Press, 2006 